\title{
Synthesis and Characterization of Activated Carbon from the Biowaste of the Plant Manihot Esculenta
}

\author{
CHUBAAKUM PONGENER ${ }^{1}$, DANIEL KIBAMI ${ }^{1}$, KAZA S. RAO $^{1}$, \\ RAJIB L. GOSWAMEE ${ }^{2}$ and DIPAK SINHA ${ }^{1 *}$ \\ ${ }^{1}$ Department of Chemistry, Nagaland University, Lumami-798627, Nagaland, India \\ ${ }^{2}$ Material Science Division, CSIR-NEIST, Jorhat-785006, Assam, India \\ dipaksinha@gmail.com
}

Received 29 September 2014 / Accepted 17 October 2014

\begin{abstract}
Carbon has been synthesized from biowaste material of the plant Manihot esculenta and its activation was done by $\mathrm{HNO}_{3}$. Surface functionality of activated carbon was studied by Bohem titration and FT-IR (Fourier transform infrared Spectroscopy) techniques whereby different functional groups such as lactonic group, carboxylic group, hydroxyl group, carbonyl group etc. were observed. From the PXRD (Powder X-ray Diffraction) analysis, the phase and the crystallite size of the activated carbon was found to be $45.56 \mathrm{~nm}$. Elemental analysis and the surface pores distribution were studied by EDX (Energy-Dispersive X-Ray) and SEM (Scanning Electron Microscope). Thermal study of the activated carbon reveals the fact that the synthesized carbon has thermal stability above $1000{ }^{\circ} \mathrm{C}$. Other physical parameters such as apparent density, ash content, volatile matter, water soluble matter, acid soluble matter, fixed carbon, $\mathrm{pH}$, iodine number and porosity were measured a analyzed in details in this paper.
\end{abstract}

Keywords: Manihot esculenta, Activated carbon, Biowaste

\section{Introduction}

Activated carbon can be manufactured from any material that has reasonable elemental carbon content ${ }^{1}$. Some of the precursors for activated carbon such as bagasse ${ }^{2}$ scrap tires and saw dust ${ }^{3}$, almond, pecan, English walnut, black walnut and macadamia nut ${ }^{4}$ pistachio $^{5}$ hazelnut shells ${ }^{6}$ rice husk ${ }^{7,8}$ rice bran ${ }^{9}$ coal, peat, coconut shell and any other inexpensive materials with high carbon content ${ }^{10-18}$. This activated carbon was used to remove organic and inorganic contaminants from water or air because of their high adsorptive capacities ${ }^{19}$. The presence of surface oxygen groups increase the sorption properties of activated carbon, thus enhance the sorption of cations and anions from aqueous solution ${ }^{19}$.

Although organic macromolecular systems carbonize to microporous carbons, they do not maximize their porous potential. That is, their adsorption capacity, measured as a micropore volume or surface area, is too low for commercial applications ${ }^{20}$. So in order to widen the porosity which can be opened to allow access to larger adsorbate molecules, there are two industrial processes used to maximize the adsorption potential. In one case, modifications 
to a carbon by gasifying agents such as carbon dioxide and water vapor, either singly or together is done after its production. This method of activation, entirely within the gas phase, is known as thermal or physical activation. In other case, suitable modifications are made to the carbonization process by additions of phosphoric acid $\left(\mathrm{H}_{3} \mathrm{PO}_{4}\right)$, or zinc chloride $\left(\mathrm{ZnCl}_{2}\right)$ or potassium hydroxide $(\mathrm{KOH})$ and potassium carbonate $\left(\mathrm{K}_{2} \mathrm{CO}_{3}\right)$ etc. Such activation processes are said to be chemical activations. As some industrial adsorption processes require "fine tuning" of the porosity of a carbon, it is possible to combine thermal and chemical activation processes to obtain a desired activated carbon ${ }^{20}$. In the present work the basic starting carbon media was prepared by chemical activation using nitric acid. The synthesized activated carbon was characterized by different techniques and details of which are discussed in this paper.

\section{Experimental}

The biowaste materials of the plant Manihot esculenta was collected washed and dried in the sun for few days. After the materials were completely dried, the materials were packed in a stainless steel container and carbonization process was carried out using Muffle furnace at around $600-800{ }^{\circ} \mathrm{C}$ for 4-6 hours in a uniform Nitrogen flow. After which the carbonized materials were ground into fine powder with mortar and pestle and washed with distilled water to remove impurities and dried in the oven at $110^{\circ} \mathrm{C}$. The dried carbon was grinned in the planetary Ball Mill at $600 \mathrm{rpm}$ for around 10 minutes to obtain uniform size.

\section{Activation of carbon by $\mathrm{HNO}_{3}$}

Around 10-15 g of carbon was taken in $500 \mathrm{~mL}$ beaker and $0.1 \mathrm{~N} \mathrm{HNO}_{3}$ solutions was added into the beaker until the carbons were fully submerged and followed by shaking for $2-3 \mathrm{~h}$ in a rotatory shaker. It was then filtered using Whatman No. 42 filter paper. The carbon was washed with $150 \mathrm{~mL}$ of double distilled water to removed excess of acid and dried in an oven at $110{ }^{\circ} \mathrm{C}$ until it was completely dried. The dried activated carbon was stored in an airtight container for further study.

\section{Characterizations of carbon}

Synthesized activated carbon was characterized by several analytical methods. Given below are the details about some physical characterization methods and its results.

\section{Moisture content}

A silica crucible was pre-heated at $110{ }^{\circ} \mathrm{C}$ for $1 \mathrm{~h}$ and allowed to cool at room temperature. $1 \mathrm{~g}$ of carbon sample was weighed and dried in a drier continuously. The drying sample was constantly reweighed at $10 \mathrm{~min}$. interval until a constant weight was obtained. The ratio of change in original weight expressed in percentage gives the moisture content.

$$
\text { Moisture content }(\%)=\frac{(C-D)}{(C-B)} \quad \times 100
$$

Where $\mathrm{B}=$ Mass of crucible $(\mathrm{g}), \mathrm{C}=$ Mass of crucible with sample $(\mathrm{g}), \mathrm{D}=$ Mass of crucible after weight loss $(\mathrm{g})^{21}$.

\section{Volatile matter}

A silica crucible was preheated in an oven to $900{ }^{\circ} \mathrm{C}$ for $10 \mathrm{~min}$ and cooled in a desiccators. $1 \mathrm{~g}$ of carbon sample was taken in a preheated silica crucible partially closed with a lid and heated at about $900{ }^{\circ} \mathrm{C}$ for $10 \mathrm{~min}$ in the oven. The crucible and its contents was retrieved and cooled in a desiccators. The loss in weight gives the volatile matter. 


$$
\text { Volatile matter }(\%)=\frac{(C-D)}{(C-B)} \times 100
$$

Where $\mathrm{B}=$ Mass of crucible $(\mathrm{g}), \mathrm{C}=$ Mass of crucible with sample $(\mathrm{g}), \mathrm{D}=$ Mass of crucible after weight loss $(\mathrm{g})^{21}$

\section{Acid insoluble matter}

An adsorbent ( $1 \mathrm{~g}$ ) was placed in an evaporating dish mixed with distilled water to thin slurry followed by addition of 5-10 $\mathrm{mL}$ of Conc. $\mathrm{HCl}$ and the mixture was digested by warming until the sample was nearly dry. The digestion was repeated three times with $5 \mathrm{~mL}$ of the acid. Then it was diluted with $100 \mathrm{~mL}$ water. It was then filtered using a previously weighed sutured crucible; the weight of the insoluble matter was calculated after drying for a constant weight at $110^{\circ} \mathrm{C}$.

$$
\text { Acid insoluble matter }(\%)=\frac{(C-D)}{(C-B)} \times 100
$$

Where $\mathrm{B}=$ Mass of crucible $(\mathrm{g}), \mathrm{C}=$ Mass of crucible with sample $(\mathrm{g}), \mathrm{D}=$ Mass of crucible after weight loss $(\mathrm{g})^{21}$

\section{Water soluble matter}

$1 \mathrm{~g}$ of carbon sample was added to $100 \mathrm{~mL}$ of distilled water and shakes thoroughly for about 30 minutes and filtered. The residue i.e., adsorbent was dried, cooled and weighted. The loss in weight was calculated, which gives water soluble matter.

$$
\text { Water soluble matter }(\%)=\frac{(\mathrm{C}-\mathrm{D})}{(\mathrm{C}-\mathrm{B})} \times 100
$$

Where $\mathrm{B}=$ Mass of crucible (g), C = Mass of crucible with sample (g), D = Mass of crucible after weight loss $(\mathrm{g})^{21}$

\section{Ash content}

A silica crucible was preheated in an oven at $900{ }^{\circ} \mathrm{C}$ for $1 \mathrm{~h}$. It was then allowed to cool in a dessicator and reweighed. $1 \mathrm{~g}$ of carbon sample was placed in the crucible and heated at $900{ }^{\circ} \mathrm{C}$ for 1 hour with lid on. The crucible and its content was then cooled in the desiccators and reweighed. The weight of the incombustible residue accounts for ash content.

$$
\text { Ash content }(\%)=\frac{(C-D)}{(C-B)} \times 100
$$

Where $\mathrm{B}=$ Mass of crucible $(\mathrm{g}), \mathrm{C}=$ Mass of crucible with sample $(\mathrm{g}), \mathrm{D}=$ Mass of crucible after weight loss $(\mathrm{g})^{21}$

\section{Fixed carbon}

Fixed carbon was obtained by using the following formula,

Fixed carbon $=$ volatile matter + moisture content + ash content -100

\section{Determination of porosity and bulk density}

A cylinder and a silica crucible were weighed and the Manihot esculenta activated carbon was added into the cylinder and reweighed. The carbon were transferred into the silica crucible and dried in the oven at $105{ }^{\circ} \mathrm{C}$ until a constant weight was obtained. The weight of the dried carbon was taken again after drying. A clean dry well corked density bottle was weighed. The bottle was filled with water, corked and reweighed followed by addition of small amount quantities of carbon into the bottles with little amount of water and weighed again. The bulk density, dry density and porosity were calculated using the following expressions ${ }^{22,23}$. 


$$
\begin{aligned}
& \text { Bulk density }=\frac{\text { Mass of wet sample }}{\text { Mass of vol. }} \\
& \text { Dry density }=\frac{\text { Mass of dry sample }}{\text { Vol. of cylinder }}
\end{aligned}
$$

Where $\mathrm{V}_{\mathrm{v}}=$ volume of void, $\mathrm{V}_{\mathrm{t}}=$ total volume

The volume of void $\mathrm{V}_{\mathrm{v}}$ was obtained by first determining the total volume of the cylinder

$$
\begin{gathered}
\text { Porosity }(\eta)=\frac{V_{v}}{V_{t}} \\
V_{t}=\pi r^{2} h
\end{gathered}
$$

Used for the experiment and also determining the volume of solid i.e. the activated carbon used

$$
\mathrm{V}_{\mathrm{s}}=\mathrm{M}_{\mathrm{s}} / \mathrm{G}_{\mathrm{s}} \rho \mathrm{w}
$$

$\mathrm{r}=$ radius of cylinder, $\mathrm{h}=$ height of cylinder, $\mathrm{M}_{\mathrm{s}}=$ mass of solid, $\mathrm{G}_{\mathrm{s}}=$ specific gravity, $\rho_{\mathrm{w}}=$ density of water

Then, volume of void $\left(\mathrm{V}_{\mathrm{v}}\right)$ was obtained as

$$
\mathrm{V}_{\mathrm{v}}=\mathrm{V}_{\mathrm{t}}-\mathrm{V}_{\mathrm{s}}
$$

\section{Specific gravity determination}

A cleaned and dried relative density bottle was weighed empty. One third of the activated carbons were put into the density bottle and weighed again. The relative density bottle was then filled with water and reweighed. Finally the bottles were emptied, cleaned of the activated carbon particles and then filled with water alone and weighed. The specific gravity was calculated ${ }^{22}$.

\section{Determination of Iodine number}

A stock solution was prepared containing $2.7 \mathrm{~g}$ of iodine crystals and $4.1 \mathrm{~g}$ of potassium iodide per liter. The prepared stock solution was standardized using a standard solution of sodium thiosulphate. Into a $100 \mathrm{~mL}$ volumetric flask, $0.5 \mathrm{~g}$ of the activated carbon and $10 \mathrm{~mL}$ of $5 \% \mathrm{v} / \mathrm{v}$ hydrochloric acid is introduced. The flask was stirred gently until the carbon was wetted. Then $100 \mathrm{~mL}$ of the stock iodine solution was added and the flask was shaken using rotary shaker for 1 hour. The mixtures were filtered through a sintered glass crucible. An aliquot portion $(20 \mathrm{~mL})$ was titrated with $0.1 \mathrm{M}$ sodium thiosulphate using starch as indicator. The concentration of iodine adsorbed by the activated carbon at room temperature was calculated as amount of iodine adsorbed in milligrams ${ }^{22}$.

$$
\frac{\mathrm{Img}}{\mathrm{g}}=\frac{(\mathrm{B}-\mathrm{S})}{\mathrm{B}} \times \frac{\mathrm{VM}}{\mathrm{W}} \times 253.81
$$

Where, $\mathrm{B}$ and $\mathrm{S}$ are the volumes of thiosulphate solution required for blank and sample titrations respectively. $\mathrm{W}$ is the mass of activated carbon sample, $\mathrm{M}$ is the concentration (mol) of the iodine solute, 253.81 is the atomic mass of iodine and $\mathrm{V}$ is $20 \mathrm{~mL}$ aliquot.

\section{Determination of $\mathrm{pH}$ and conductivity}

$1.0 \mathrm{~g}$ of activated carbon was weighed and transferred into a beaker. $100 \mathrm{~mL}$ of distilled water was measured and added and stirred for one hour ${ }^{21}$. The samples were allowed to stabilize before the $\mathrm{pH}$ and conductivity was measured using a $\mathrm{pH}$ meter (Thermo ScientificOrion 4 star, ISE). 


\section{Determination of zero point charge $\left(\mathrm{pH}_{z p c}\right)$}

Zero point charge is the $\mathrm{pH}$ at which the external surface charge is zero ${ }^{24}$. The $\mathrm{pH}$ point of zero charge determination $\left(\mathrm{pH}_{\mathrm{zpc}}\right)$ of the activated carbons were carried out by adding $0.1 \mathrm{~g}$ of activated carbons to $200 \mathrm{~mL}$ solution of $0.1 \mathrm{M} \mathrm{NaCl}$ whose initial $\mathrm{pH}$ has been measured and adjusted with $\mathrm{HCl} 0.1 \mathrm{~N}$ or $\mathrm{NaOH} 0.1 \mathrm{~N}$ solutions. The containers were sealed and placed on a shaker for $24 \mathrm{~h}$ after which the $\mathrm{pH}$ was measured. $\mathrm{The}_{\mathrm{pH}}$ occurs when there was no change in the $\mathrm{pH}$ after contact with adsorbent ${ }^{22}$. The $\mathrm{pHzpc}$ is the point where the curve $\mathrm{pH}_{\text {final }} v s$. $\mathrm{pH}_{\text {initial }}$ crosses the line $\mathrm{pH}_{\text {(final) }}=\mathrm{pH}_{\text {(initial) }}$ taken as the $\mathrm{pH}_{\mathrm{pzc}}$ of the given carbon ${ }^{25}$.

\section{Determination of oxygen containing functional groups}

The Boehm titration method was used for the determination of oxygenated surface group ${ }^{26,27}$. $1.0 \mathrm{~g}$ of the activated carbons were kept in contact with $15 \mathrm{~mL}$ solution of $\mathrm{NaHCO}_{3}(0.1 \mathrm{M})$, $\mathrm{Na}_{2} \mathrm{CO}_{3}(0.05 \mathrm{M})$ and $\mathrm{NaOH}(0.1 \mathrm{M})$ for acidic groups and $0.1 \mathrm{M} \mathrm{HCl}$ for basic groups /sites respectively at room temperature for more than 2 days. Subsequently, the aqueous solutions were back titrated with $\mathrm{HCl}(0.1 \mathrm{M})$ for acidic and $\mathrm{NaOH}(0.1 \mathrm{M})$ for basic groups. The numbers of acidic sites of various types were calculated under the assumption that $\mathrm{NaOH}$ neutralizes carboxylic, phenolic and lactonic groups and that $\mathrm{Na}_{2} \mathrm{CO}_{3}$-carboxylic and lactonic and $\mathrm{NaHCO}_{3}$ only carboxylic groups. The difference between the groups titrated with $\mathrm{Na}_{2} \mathrm{CO}_{3}$ and those titrated with $\mathrm{NaHCO}_{3}$ is assumed to be lactones and the difference between the groups titrated with $\mathrm{NaOH}$ and those titrated with $\mathrm{Na}_{2} \mathrm{CO}_{3}$ is assumed to be phenol ${ }^{22}$. The number of surface basic sites was calculated from the amount of hydrochloric acid, which reacted with the carbon. Neutralisation points were known using $\mathrm{pH}$ indicators of phenolphthalein solution for titration of strong base and strong acid, methyl red solution for weak base with strong acid and $\mathrm{pH}$ together.

\section{Scanning electron microscopy (SEM) study}

The surface morphology of the Manihot esculenta activated carbon was studied by SEM techniques using SEM-JEOL JMS 6390 LV instrument at different magnification Figure 1 and Figure 2.

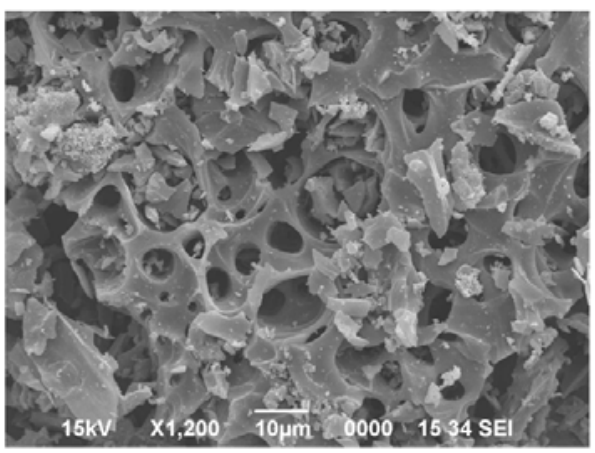

Figure 1. SEM image of manihot esculenta activated carbon at 1200 magnification showing different pores size and shape

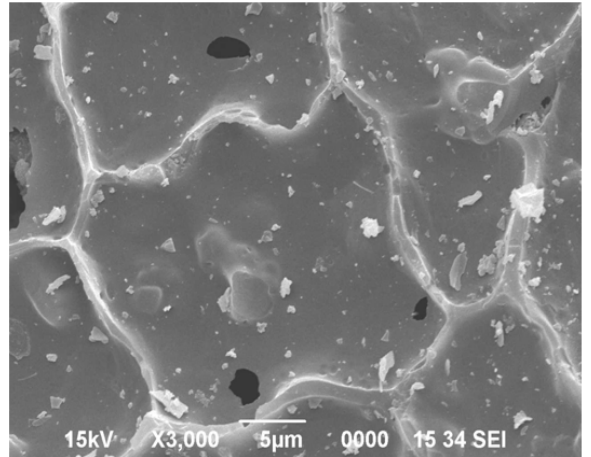

Figure 2. SEM image of Manihot esculenta activated carbon at 3000 magnification

\section{Energy-Dispersive $x$-ray $(E D X)$ study}

The results of EDX analysis of the synthesized activated carbon of Manihot esculenta is shown in Figure 3. 


\section{FT-IR study}

FT-IR analysis was done using FT-IR (model -Perkin Elmer spectrum system 200) by using $\mathrm{KBr}$ pellets in the range of $400-4000 \mathrm{~cm}^{-1}$ at the spectral resolution of $4 \mathrm{~cm}^{-1}$. FT-IR absorption spectrum is shown in Figure 4.

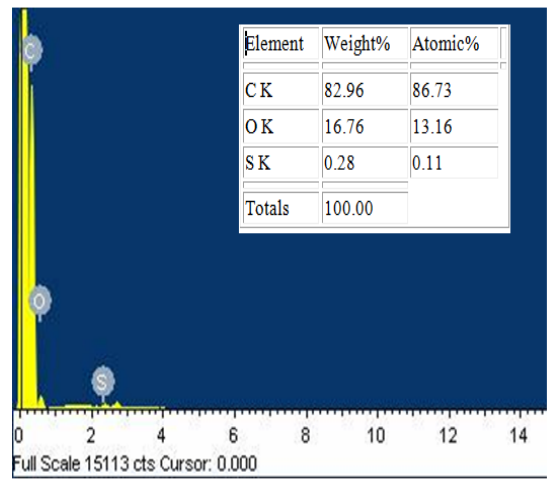

Figure 3. EDXA spectra of Manihot esculenta activated carbon

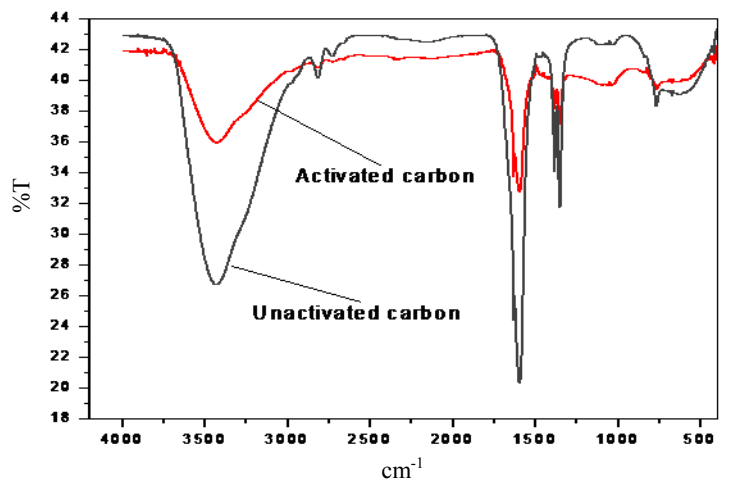

Figure 4. FT-IR spectra of Manihot esculenta unactivated carbon and activated carbon

Thermo gravimetric analysis (TGA) study

Thermo gravimetric analysis was carried out by using TA instrument (SDT Q 600, M/S TA Instruments, USA) using alumina as a reference at a heating rate of $20{ }^{\circ} \mathrm{C} /$ minute under argon atmosphere at the flow rate of $100 \mathrm{mg} / \mathrm{L}$. Figure 5 present the thermogram of Manihot esculenta activated carbon.

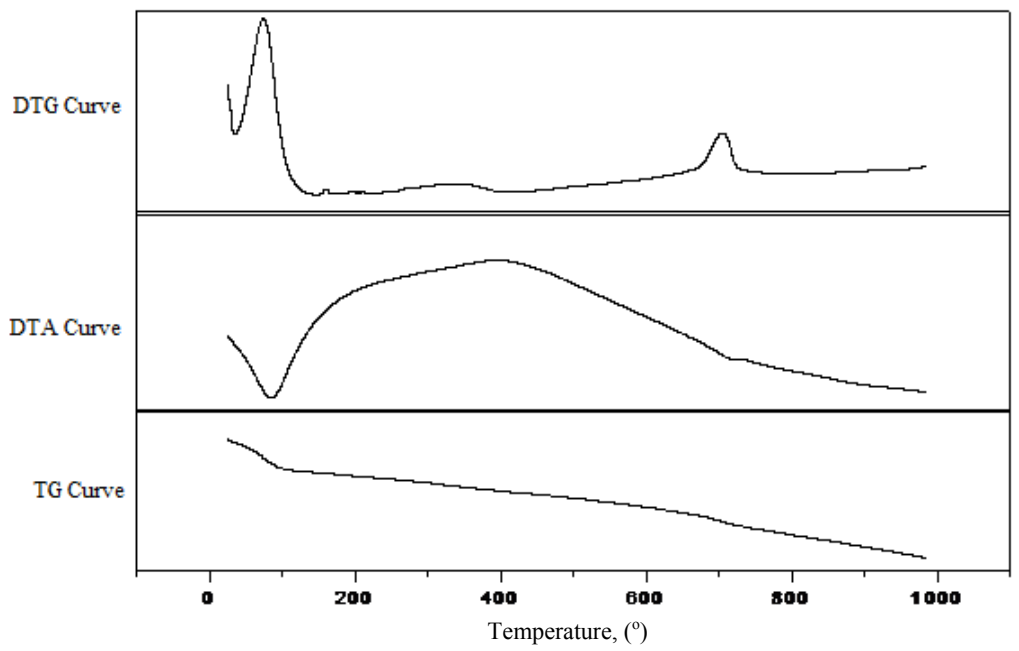

Figure 5. Thermogram of Manihot esculenta activated carbon

\section{Powder x-ray diffraction (PXRD) study}

PXRD analysis was done using XRD (Model Rigaky-Ultimaiv Japan) using CuKo radiation at the scanned rate of 0.2 degree per minute. PXRD spectra of Manihot esculenta activated carbon is shown in Figure 6. 


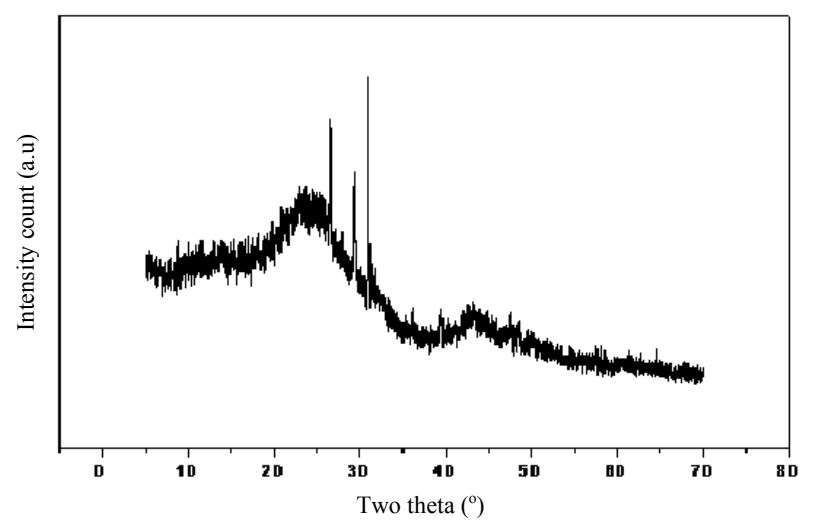

Figure 6. PXRD spectra of Manihot esculenta activated carbon

The Scherrer equation is given $\mathrm{as}^{28}$

$$
\tau=\frac{K \lambda}{\beta \cos \theta}
$$

Where, $\mathrm{K}$ is the shape factor. The shape factor correlates the size of the sub-micrometer particles or crystallite in a solid to the broadening of a peak in a diffraction pattern. $\lambda$ is the $\mathrm{x}$-ray wavelength, typically $1.54 \AA(\mathrm{CuK} \alpha=1.54) \beta$ is the line broadening at the half the maximum intensity (FWHM) in radian and $\theta$ is the Bragg's angel. The dimension shape factor has a typical value of about 0.9 but varies with the actual shape of the crystallite. The Scherrer equation is limited to nano scale particle but applicable to grain larger than $0.1 \mu \mathrm{m}$.

\section{Results and Discussion}

Table 1 present the various physical characterisation of Manihot esculenta activated carbon.

Table 1. The details about physical characterization

\begin{tabular}{|c|c|c|}
\hline S. No. & Parameters & Manihot esculenta activated carbon \\
\hline 1. & Apparent density & $0.4366 \mathrm{~g} \mathrm{~mL}^{-1}$ \\
\hline 2. & Moisture Content, \% & 12.87 \\
\hline 3. & Volatile matter, $\%$ & 1.00 \\
\hline 4. & Ash Content, \% & 12 \\
\hline 6. & Fixed carbon, $\%$ & 74.13 \\
\hline 7. & Acid-soluble matter, $\%$ & 0.8 \\
\hline 8. & Water soluble matter, $\%$ & 0.45 \\
\hline 9. & Iodine Number & $703.743 \mathrm{~m}^{2} \mathrm{~g}^{-1}$ \\
\hline 10. & Porosity & 0.935 \\
\hline 11. & $\mathrm{pH}$ & 6.80 \\
\hline 12. & Conductivity & $123.6 \mu \mathrm{s}$ \\
\hline 13. & $\mathrm{pH}_{\mathrm{zpc}}$ & 8.30 \\
\hline \multirow[t]{6}{*}{14.} & \multicolumn{2}{|c|}{ Surface acid groups, meq $\mathrm{g}^{-1}$ (Boehm titration) } \\
\hline & Carboxyl & 0.4 \\
\hline & Lactonic & 1.00 \\
\hline & Phenolic & 1.2 \\
\hline & Carbonyl & 1.3 \\
\hline & Total basic groups, meq $\mathrm{g}^{-1}$ & 5.87 \\
\hline
\end{tabular}


The apparent density is very useful in estimating the packing volume of activated carbon or to determine the grade of carbon needed for an existing system ${ }^{21}$. The observed apparent density of Manihot esculenta activated carbon was $0.436 \mathrm{~g} \mathrm{~mL}^{-1}$. The relatively low density of activated carbons is attributed to random arrangement of micro-crystallites and with strong cross-linking which produce porous structure ${ }^{21}$. The moisture content, volatile matter and ash content of carbon was found to be $12.87 \%, 1.00 \%$ and $1.2 \%$ respectively which can be consider as a good source of carbon. The low value of matter soluble in acid $(0.8 \%)$ indicates that the Manihot esculenta activated carbon is insoluble in acid, therefore can be engaged in treating acidic water in nature ${ }^{28}$. Matter soluble in water was $0.45 \%$ indicating that the carbon is almost insoluble in water and hence can be used for water analysis. The $\mathrm{pH}$ value was 6.80 which are in optimum neural medium range 6.4 to 7.2 for pure water. Carbons of $\mathrm{pH} 6-8$ are useful for most applications ${ }^{8}$. The conductivity for Manihot esculenta activated carbon was $123.6 \mu \mathrm{S}$. The conductivity test is important because it shows the presence of leachable ash which is considered an impurity and undesirable in activated carbon $^{23}$. Conductivity ranges from $51.85 \mu \mathrm{S}$ to $70.75 \mu \mathrm{S}$ is considered as good conductivity for activated carbons ${ }^{29}$.

The $\mathrm{pH}_{\mathrm{zpc}}$ values of Manihot esculenta was 8.3 indicating that the surface is positively charged. When the $\mathrm{pH}>\mathrm{pH}_{\mathrm{zpc}}$ the surface of the carbon is rendered negatively charged, because of the dissociation of the acidic functionalities, releasing protons into the medium. Thus, leaving negatively charged surface on the carbon. On the other hand, when the $\mathrm{pH}$ $<\mathrm{pH}_{\mathrm{zpc}}$, basic sites combine with protons from the medium to leave a positively charged surface $^{30}$. From Table 1 it can be seen that the total basic groups is greater than the total acidic groups (due to carboxylic, lactonic, phenolic and carbonyl groups). Boehm states that the chemisorption of oxygen suggests that the basicity may be due to oxygen functional groups, and the existence of pyrone-type structures on the edges of the polyaromatic layers has been suggested ${ }^{21}$. It has been established that iodine number (in $\mathrm{mg} \mathrm{g}^{-1}$ ) gives an estimate of the surface area (in $\left.\mathrm{m}^{2} \mathrm{~g}^{-1}\right)^{31}$ and it measures the porosity of pores with dimensions $\geq 1.0 \mathrm{~nm}$. Iodine numbers for Manihot esculenta activated carbon was found to be 703 and this higher level of iodine number reveals that the presence of high porosity in the carbon.

SEM micrographs of the activated carbon gives a clear picture of the porosity of an adsorbent and also shows complex disorganized surface structures of different open pore sizes and shapes. Figure $1 \& 2$ show the SEM micrograph at a magnification of 1300 and 3000 respectively. The surface corrugation is clearly visible from the SEM images which may be due to $\mathrm{HNO}_{3}$ treatment. Manihot esculenta activated carbon possesses many pores in a honeycomb like shape which are clearly visible on the surface. This shows that $\mathrm{HNO}_{3}$ activation is effective to create well developed pores distribution on the surface of the precursor, thus leading to large surface area and porous structure of the activated carbon. Thus the presence of different pores sizes in Manihot esculenta activated carbon may greatly influences the adsorption process. Figure 3 shows the elemental percentage composition of $\mathrm{C}, \mathrm{O}$ and $\mathrm{S}$ in the synthezised activated carbon where $\mathrm{C}$ contain was found to be $82.96 \%$ and that of $\mathrm{O}$ and $\mathrm{S}$ is found to be $16.76 \%$ and $0.28 \%$ respectively.

The presence of oxygen and aromatic structures were identified in prepared activated carbons by FT-IR analysis (Figure 4). Surface chemical groups were detected by absorption bands assigned to carboxyl, carbonyl, phenolic, ethers and surface hydroxyl groups. Figure 4 shows the FT-IR spectra of Manihot esculenta activated carbon. A very prominent peak at $3430 \mathrm{~cm}^{-1}$ is due to the absorption of water molecules as result of an $\mathrm{O}-\mathrm{H}$ stretching mode of hydroxyl groups and adsorbed water, while the band at $2810 \mathrm{~cm}^{-1}$ is attributed to $\mathrm{C}-\mathrm{H}$ stretch 
or $\mathrm{N}-\mathrm{CH}_{3}$ which may be due to the interaction $\mathrm{N}$ of $\mathrm{HNO}_{3}$ with the surface carbon. The band of asymmetric stretching at lower wave numbers indicates the presence of strong hydrogen bonds. A small peak at 2929 may be attributed to methylene C-H stretch. The peaks at $1631 \mathrm{~cm}^{-1}$ is due to the presence of amide group. The band appearing at $1594 \mathrm{~cm}^{-1}$ for carbon samples has been interpreted unequivocally. This has been assigned to aromatic ring stretching coupled to highly conjugated carbonyl groups or attributed to the stretching vibrations of $\mathrm{C}=\mathrm{O}$ moieties of conjugated systems such as diketone, keto ester and keto-enol structures ${ }^{21}$. Bands at $1024 \mathrm{~cm}^{-1}$ correspond to alcoholic C-O stretching vibration. Bands observed below $950 \mathrm{~cm}^{-1}$ are characteristic of out of plane deformation vibrations of $\mathrm{C}-\mathrm{H}$ group in aromatic structures.

TGA studies reveal the stability of carbon under high temperature (Figure 5), initially a weight loss occurs at around 74 degree $\mathrm{C}$, with a percent mass lose of $8.324 \%$ which may be due to the presence of hygroscopic molecule like water and other volatile matter, impurities etc. Again a small weight change was observed at around 705 degree $\mathrm{C}$, with a percent mass loss of $22.214 \%$ which may be due to the loss of Carbon dioxide and carbon monoxide. Finally at around $1000{ }^{\circ} \mathrm{C}$ Manihot esculenta activated carbon show a percent mass lose of $34.62 \%$ with $65.38 \%$ remain as unburn. Thus it is clear that the Manihot esculenta activated carbon show excellent thermal stability. Thus from thermo gravimetric curves the weight loss can be observed which can be assumed that wet oxidation of activated carbon with $\mathrm{HNO}_{3}$ caused a considerable degree of functionality formation on carbon surface. These functionalities become attached to a high degree that desorption primarily as $\mathrm{CO}_{2}$ and /or $\mathrm{CO}$, requires high energy. Hence the weight loss shown in the thermo gram is distributed over a wide temperature range. These results corroborate the above observations concerning the effect of oxidation by $\mathrm{HNO}_{3}$ on the surface chemical nature of active carbon. These studies also support the presence of various functional groups observed in the FT-IR. Figure 6 shows the PXRD spectra of Manihot esculenta activated carbon, By using Scherrer equation, from the XRD data the crystallite peak size for Manihot esculenta at $(1,0,4)$ was calculated to be $45.56 \mathrm{~nm}$.

\section{Conclusion}

The prepared activated carbon from biomaterials Manihot esculenta has been successfully synthesized followed by $\mathrm{HNO}_{3}$ treatment. The physicochemical characteristics and observations from Boehm titration indicated that presence of basic groups is more when compared to acidic group in these carbons; the $\mathrm{pH}$ value is less than its corresponding $\mathrm{pH}_{\mathrm{zpc}}$ value. This indicates that the surface is positively charged which favours the adsorption of anions. Surface chemical groups were detected by absorption bands assigned to carbonyl, ethers and surface hydroxyl groups by the FT-IR. Carbon and oxygen elements composition is given by the EDAX technique. Since the prepared activated carbon exhibits well defined porosity of different shape and sizes and also because of the presence of different functional groups the carbon was used for fluoride, dye and microbial removal from aqueous solutions.

\section{Acknowledgement}

One of the author Chubaakum Pongener is grateful to UGC New Delhi for Rajiv Gandhi National Fellowship.

\section{References}

1. Qureshi K, Bhatti I, Kazi R and Ansari A K, Int. J Chem Bio Eng., 2008. 1(3), 144-148.

2. Ahmedna M, Marshall W E and Rao R M, Bioresour Technol., 2000, 71(2), 103-112; DOI:10.1016/S0960-8524(99)90069-X 
3. Nadhem K H, Xiao D C, Mohaqmmed M F and Max G L, Chem Eng J., 2001, 84(2), 95105; DOI:10.1016/S1385-8947(01)00194-2

4. Christopher A T, Wayne E M and Mitchell M J, J Chem Technol Biotechnol., 1998, 72(3), 255-263; DOI:10.1002/(SICI)1097-4660(199807)72:3<255::AIDJCTB890>3.0.CO;2-P

5. Wartelle L H and Marshall W E, J Chem Techno Biotechnol., 2001, 76(5), 451-455; DOI:10.1002/jctb.408

6. Kobya M, Adsorpt Sci Technol., 2004, 22(1), 51-64.

7. Nevin Y and Vadettin S, J Carbon, 2000, 38, 1943-1945.

8. Okiemmen F, Okiemen C and Wuana A, J Chem Soc Nigeria, 2007, 32, 126-136.

9. Mubeena A, Bhanger M I, Shahid I and Moosa H S, J Agri Food Chem., 2005, 53(22), 8655-8662; DOI:10.1021/jf058060h

10. Laine A J and Calafat M L, J Carbon, 1989, 27(2), 191-195.

11. Ahmadpour A and Do D D, J Carbon, 1996, 34(4), 471-479

12. Di P R and Egiebor N O, Fuel Process Technol., 1996, 46(3), 157-169; DOI:10.1016/0378-3820(95)00054-2

13. Usmani T H, Ahmed T W, Ahmed S Z and Yousufzai A H K, J Carbon, 1996, 34(1), 77-82.

14. Toles C, Rimmer S and Hower J C, J Carbon, 1996, 34(11), 1419-1426.

15. Tsay W T, Chang C Y and Lee S L, Bioresour Technol., 1998, 64(3), 211-217; DOI:10.1016/S0960-8524(97)00168-5

16. Kailappan R, Gothandapani L and Viswanathan R, Bioresour Technol., 2000, 75(3), 241-243; DOI:10.1016/S0960-8524(00)00056-0

17. Tsai W T, Chang C Y, Wang S Y, Chang C F, Chien S F and Sun H F, Bioresour. Technol., 2001, 78(2), 203-208; DOI:10.1016/S0960-8524(00)00111-5

18. Diao Y, Walawender W P and Fan L T, Bioresour. Technol., 2002, 81(1), 45-52; DOI:10.1016/S0960-8524(01)00100-6

19. Sreenivasa R V, Kaza S R, Nageswara M R and Upasanab B S, Asian J Biochem Pharm Res., 2011, 2(1), 567-584.

20. Marsh H and Rodriguez-Reinoso F, Elsevier Sci Technol Books, 2006, 243.

21. Rao M N, Chakrapani Ch, Reddy B V R, Babu Ch S, Rao Y H, Rao K S and Rajesh K, Int J Appl Bio Pharm Technol., 2011, 2(3), 610-618.

22. Ekpete O A and Horsfall M JNR, Res J Chem Sci., 2011, 1(3), 10-17.

23. Verla A W, Horsfall (Jnr) M, Verla E N, Spiff A I and EkpeteO A, Asian J Nat Appl Sic., 2012, 1(3), 39-50.

24. Marsh H and Rodriguez-Reinoso F, Elsevier Sci Technol. Books, 2006, 401.

25. Newcombe G, Hayes R and Drikas M, Surf A, 1993, 78, 65-71.

26. Boehm H P, Angew Chem Int Ed., 1966, 5(6), 533-544;

DOI:10.1002/anie.196605331

27. Boehm H P, Diehl E, Heck W and Sappok R, Angew Chem Int Ed., 1964, 3(10), 669-677; DOI:10.1002/anie.196406691

28. Scherrer P, Nachr Ges Wiss Göttingen, 1918, 26, 98-100.

29. Khadija Q, Inamullah B, Rafique K and Abdul K A, Int J Chem Biomol Eng., 2008, 1(3), 145-149.

30. Menendez-Diaz J A and Martln-Gullonb I, Academic Press, 2006, 11. ISBN-13: 9780-12-370536-5.

31. Girgis B S and El-Hendawy A A, Micro Meso Mater., 2002, 52(2), 105-117; DOI:10.1016/S1387-1811(01)00481-4 